\title{
Synthesis of tetrahydropiridines by one-pot multicomponent reaction using Niobium Pentachloride.
}

\section{Lucas Michelão Martins ${ }^{1,{ }^{*}}$, Bruno Henrique Sacoman Torquato da Silva, ${ }^{1}$ e Luiz Carlos da Silva-Filho'}

\author{
${ }^{1}$ Chemistry Departament, Faculty of Sciences, UNESP-Bauru, Av. Eng. Luiz Edmundo Carrijo Coube, 14-01, \\ CEP 17033-360,Vargem Limpa, Bauru, S.P. *e-mail: luke16lanceiros@yahoo.com.br
}

Keywords: Niobium Pentachloride, Multicomponent reaction, Tetrahydropiridines derivative, Hetehocycles.

\section{INTRODUCTION}

Tetrahydropiridines occurs in nature in great quantities, and are known to be important in the pharmaceutical industry. Some of them also act as therapeutic agents, exhibit antihypertensive, antibacterial, anticonvulsant and anti-inflammatory activities.

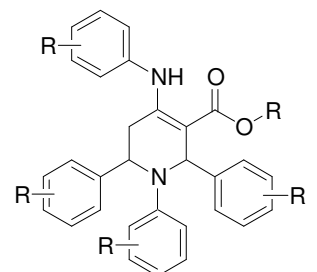

Figure 1. Tetrahydropiridine Derivative.

Knowing that Tetrahydropiridines derivatives can be synthesized from the Multicomponent reaction (MCRs) in the presence of different catalysts ( $\mathrm{InCl}_{3}$, TBATB, CAN, BDMS and others), ${ }^{2}$ we present the synthesis using $\mathrm{NbCl}_{5}$.

\section{RESULTS AND DISCUSSION}

In this work, we performed the Multicomponent Reaction between aniline derivatives(1-3), Benzaldehyde (4) and a $\beta$-ketoester, both methyl (5) and ethyl (6) acetoacetate. The aniline derivatives were aniline (1), $p$ bromoaniline (2) and $p$-anisidine (3) in the presence of $\mathrm{NbCl}_{5}$. The reactions were carried out under nitrogen atmosphere, at room temperature and in anhydrous solvent $\left(\mathrm{CH}_{3} \mathrm{CN}\right)$, using $1 \mathrm{mmol}$ of $\mathrm{NbCl}_{5}$. The stoichiometric ratio 2:2:1 (aldehyde:aniline: $\beta$ ketoester) in the presence of catalyst was found to be the most suitable condition for obtaining functionalized tetrahydropiridines.

The reaction proceeded smoothly at room temperature, the reactions were monitored for a maximum time of 24 hours, since, for longer times was not observed significant changes in products yields, for all tetrahydropiridine derivatives synthetized. The product obtained was purified by column chromatography. The products were isolated and characterized by spectroscopic and

$14^{\text {th }}$ Brazilian Meeting on Organic Synthesis - $14^{\text {th }}$ BMOS - September 01-05, 2011-Brasilia, Brazil $\mathrm{NbCl}_{5}$. conditions. CBMM for $\mathrm{NbCl}_{5}$ samples. J. 2005, 39, 453 spectrometric methods. The results are summarized in scheme 1 and table 1.
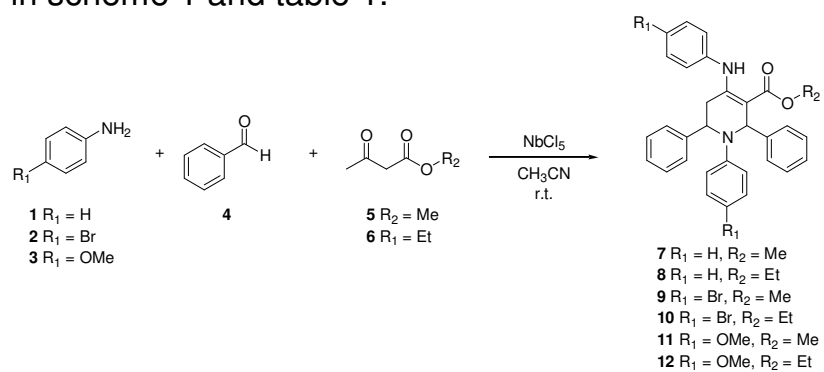

Scheme 1. MCRs catalyzed by $\mathrm{NbCl}_{5}$.

Table 1. Results obtained in MCRs in the presence of

\begin{tabular}{ccc}
\hline Aniline & $\boldsymbol{\beta}$-Ketoacid & Yields (\%) \\
\hline $\mathbf{1}$ & $\mathbf{5}$ & 49 \\
\hline $\mathbf{1}$ & $\mathbf{6}$ & 60 \\
\hline $\mathbf{2}$ & $\mathbf{5}$ & 69 \\
\hline $\mathbf{2}$ & $\mathbf{6}$ & 66 \\
\hline $\mathbf{3}$ & $\mathbf{5}$ & 62 \\
\hline $\mathbf{3}$ & $\mathbf{6}$ & 70 \\
\hline
\end{tabular}

\section{CONCLUSION}

In conclusion, we describe a novel, efficient, and practical methodology for the preparation of tetrahydropiridines derivatives through Multicomponent reaction. The method offers several advantages such as Atom economy, good yields, environmentally benign, and mild reaction

\section{ACKNOWLEDGEMENTS}

The authors thanks to FAPESP and PROPe-UNESP for financial support. We also thank

\section{REFERENCES}

1 Gwaltney, S. L.; et. al. Bioorg. Med. Chem. Lett. 2003, 13, 1359. b)Dunbar, P. G.; et. al. J. Med. Chem. 1994, 37, 2774.; c)Morale, M. C.; et. al. Neuroscience 2006, 138. 869.; d) Kadieva, M. G.; et. al. Pharm. Chem.

a) Clarke, P. A.; et. al. Synthesis 2008, 21, 3530.; b) Clarke, P. A.; et al. Tetrahedron Lett. 2007, 48, 5209.; c) Khan, A. T.; et al. Tetrahedron Lett. 2010, 51, 4419.; d) Wang, H.-J.; et al. ACS Comb. Sci. 2011, 13, 181.; e) Khan, A. T.; et al. J. Org. Chem. 2008, 73, 8398. 